\title{
Unraveling Valuable Traits in Ethiopian Grain Legumes Research Hastens Crop Intensification and Economic Gains: A Review
}

\author{
Asnake Fikre \\ Ethiopian Institute of Agricultural Research, Ethiopia
}

Copyright $\bigcirc 2016$ by authors, all rights reserved. Authors agree that this article remains permanently open access under the terms of the Creative Commons Attribution License 4.0 International License.

\begin{abstract}
Grain legumes are principal components of the Ethiopian cropping system. They stand second to cereals both in production and area coverage. Research for development over the last four decades has produced significant progress in productivity, quality, marketability and use values of these crops. Over the last two decades alone, productivity has more than doubled, market values and volumes improved remarkable, the number of household engaging in the sector increased dramatically. The effect of target trait breeding in the sector has enhanced economic, social and biological benefits with high impacts. This brought about intensification based agricultural system as a pathway of profitability in the sector. However, there have still been challenges to tap the potential of the sector. The role of key institutions in the sector is of paramount importance. The future dimension needs even far more innovative approaches and applications of advanced techniques for the sector to remain competent. The review paper tries to present the interactions within and among the research and development entities.
\end{abstract}

Keywords Grain Legumes, Yield Gain, Traits, Intensification

\section{Introduction}

Grain legumes constitute critical components in the cropping systems of the Ethiopian agriculture mainly as precursor crops with cereals accounting for one in every ten of the farm plots. Among the major grain legumes are faba bean, chickpea, lentil, field pea, common bean and soybean. It is very common to get shared common agroecology and overlay, either through crop rotation, intercropping or any other form, of faba bean in the wheat based system, chickpea in the tef and sorghum based system, and beans in dryland cropping system of maize or sorghum or tef, and soybean in the maize based cropping systems (Figure 1). This means that grain legumes are produced in a rotation system with cereals. In Ethiopia, production of the grain legumes is second to cereals. Based on the Ethiopian Central Statistical Agency (CSA) data between 1996 and 2015, the area has expanded from 910,000 to 1,559000 ha $(71 \%)$, the productivity has moved from 0.89 to $1.72 \mathrm{t} / \mathrm{ha}(93 \%)$, and the total production increased from 802,000 to $2,671,834 \mathrm{MT}$ (233\%). There are some 8 million households (about $75 \%$ of the total farming community) involved in grain legumes production as part of livelihood endeavor. The rate of gain on production and productivity for each hectare increment in area over those two decades alone was about 3.3 and 1.3 times, respectively. This renders the Ethiopian grain legumes industry one of the top grain legumes hub of Africa.

The $68^{\text {th }}$ United Nations General Assembly in 2013 has declared 2016 as the "International Year of Pulses" in recognition of their critical contribution to global food security [http://www.un.org/en/ga/search/view_doc.asp? symbol=A/RES/68/231\&referer=http://www.un.org/en/eve nts/observances/years.shtml\&Lang=E]. This has been owing to noting that, these crops are used, among others, for oil extraction and as rich source of plant-based protein for humans and animals. It is also based on: 1) recalling that the initiatives of the World Food Programme and others use pulses as a critical part of the general food basket, desiring focus on the role that pulses play as part of sustainable food production aimed towards food security and nutrition; 2) recognizing that pulses are leguminous plants with nitrogen-fixing properties and thereby contribute to increasing soil fertility and have a positive impact on the environment; 3 ) recognizing the health attribution of pulses as part of a healthy diet to address obesity, and help manage chronic diseases such as diabetes, coronary conditions and cancer; and 4) believing that such a celebration would create a unique opportunity to encourage connections throughout the food chain that would better utilize pulse-based proteins, further global production of pulses, better utilize crop rotations and address the challenges in the trade of pulses.

Grain legumes play an important role in the Ethiopian 
cropping and dietary systems. Research undertakings have been focusing on marketable trait development in each of the legumes through the conventional breeding approaches. Favorable traits including seed size, seed color, nutritional quality, seed shape, taste are among the major ones. Along with desired traits, the breeding lines are also developed for resistance against the bio-threats of which the major ones that deserve mentioning are rust (Uromyces cicer-arietini ) in lentil, bean stem maggot in haricot bean, fusarium wilt (Fusarium oxysporum $f_{s p}$. ciceris) and ascochyta blight (Ascochyta rabiei) in chickpea, chocolate spot (Botrytis fabae) in faba bean [1]. Those underlying efforts over the four decades are source Ethiopia's competitiveness in the sector. This means also intensification has been backed by technologies and innovations.

As valuable as current pulse varieties are, however, it is essential that grain legumes continue to be improved to become productive and resilient enough to meet the challenges of the $21^{\text {st }}$ century including population growth, climate change, and land degradation. The global research and development investment is sharply inclined to few cereals, and pulses are hardly competitive in sharing the resources. Given this, this paper aims at: 1) showing the progress and shifts in grain legumes improvement programs as driven by the national agricultural research systems (NARs); 2)Instigating the competitive trait-based values of the sector in terms seeking investment and attention; and 3)Arguing the complimentarily and the competitiveness of the sector in the smallholder cropping system.

This review paper tries to highlight researchable issues, method of analysis, approaches and outputs of the major grain legume crops research in Ethiopia. The intention of doing this is to evaluate progress in the improvement of the crops, along with cross validation of the value chain information in line with institutional arrangements, stakeholder perceptions and sector policy directions manuscript. The review has been structured on the premises of identified themes including ecological and, biological responses, market and seed system of grain legumes with a view to gauging the progress in improvement of economic traits of interest.

\section{Agro-ecological Adaptation Traits}

Ethiopia is endowed with diverse agro-ecological systems suitable for the growth of diverse grain legume crops. Being near the equator and having an extensive altitude range, the country has got a wide range of climatic features suitable for different agricultural production systems. Climatic heterogeneity is a general characteristic of the country [9]. These diversities are also explained by the cropping system where often cereals indicated in Figure one are being shared by legumes suitable as eco-overlap, and are produced alternatively, as explained earlier. Overall, the spatial coverage of grain legumes in Ethiopia spans over more than $90 \%$ of the cultivated land of the country.
Breeding programs in grain legumes have attempted towards improving ecological adaptive traits in their variety development design of efforts targeting the different agroe-cologies by manipulating phenological traits (maturity period), tolerance (moisture stress, thermal stress), physiological adjustment traits, root traits, and morphological traits. This by itself is predominantly dictated by the resultant of Growing Degree Days [GDD $=($ Tmax + Tmin) $/ 2$ - Tbase] and moisture levels. This phenomenon is further complimented by genetic factors where the research system has developed in response to this.

In faba bean breeding program, there is a wide gap in phenological traits of the developed varieties so far as a result of the ecology-targeted breeding [2]. However, it was indicated that trait values could be varying based on the environmental responses [3]. Among the released faba bean varieties, the minimum date range in flowering reaches $44 \%$, and this goes from 43 days in Obse variety to 61days in Kuse variety. Similarly the minimum maturity date accommodates about $67 \%$ variation, and this is explained by 87 days for Obse variety to 145 days for CS20DK. This, in turn, indicates broad the spatial coverage in the continuum of ecological variability covered by different genetic elasticity variety groups developed in between the two ranges. Ecological adaptive traits are key contributors of the faba bean productivity responses with the yield regression line between 2000 and 2010 surpassing a ton/ha on national average $\left(y=0.211 x+10.686 ; R^{2}=0.53\right)[2]$. Some $25 \%$ of the varieties were developed to adapt to water logging condition, which is a common phenomenon in the Vertisols areas of faba bean production.

Similarly, all the 20 varieties of chickpea released so far cover maturity days ranging between 86 days for Minjar variety to 122 days for Teji variety, whereas the rest of the varieties mature between these ranges. Another study on chickpea germplasm clustering to suit agro-ecological areas using the bi-plot techniques revealed different assortment responses of the germplasm with respect to different traits (seed weight, grain yield, etc.)[12]. The molecular and genetic analysis of drought and heat tolerance in chickpea indicated the presence of substantial variability for use of the genetic resources base in the breeding program. Accordingly, a study using 18 SNPs from 5 genes (ERECTA, 11 SNPs; ASR, 4 SNPs; DREB, 1 SNP; CAP2 promoter, 1 SNP and AMDH, 1SNP) showed significant association of markers with different economic traits [10]. Upon revalidation, the released varieties of chickpea clustered based on agro-ecological adaptation mechanisms and stability, and it was possible to identify discriminative, suitable and unsuitable environments based on the stable or variable responses of the varieties tested under the four divergence environments [11]. A similar agro-ecological adaptation rating study has reaffirmed different genetic makeup in small red beans varieties depicting different responses. The environmental scaling analysis has been used in mapping the suitability of the varieties or dissociated lines to the defined environments, as a case shown in chickpea[12] (Figure 2). 


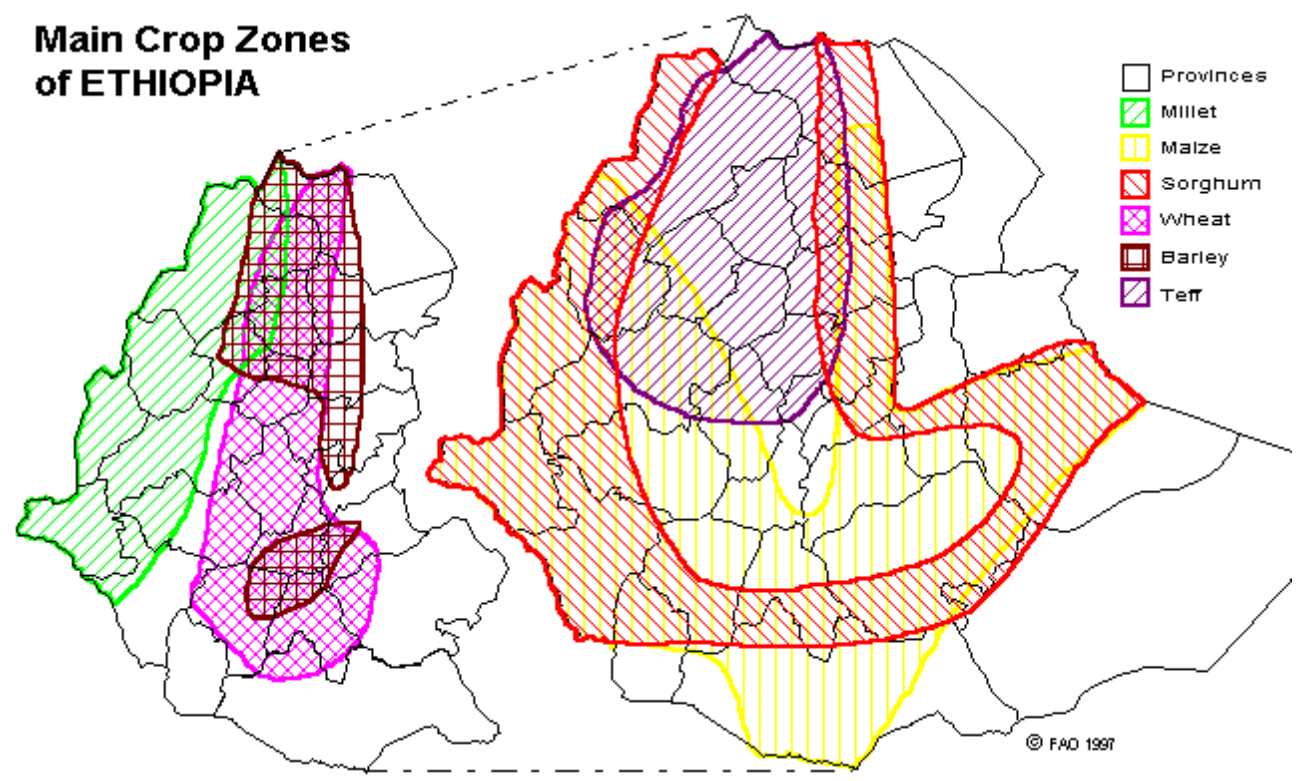

Figure 1. Spatial distribution of major cereals grown in Ethiopia, to be overplayed with respective associations of grain legumes

\section{GGE biplot for SY (environment scaling)}

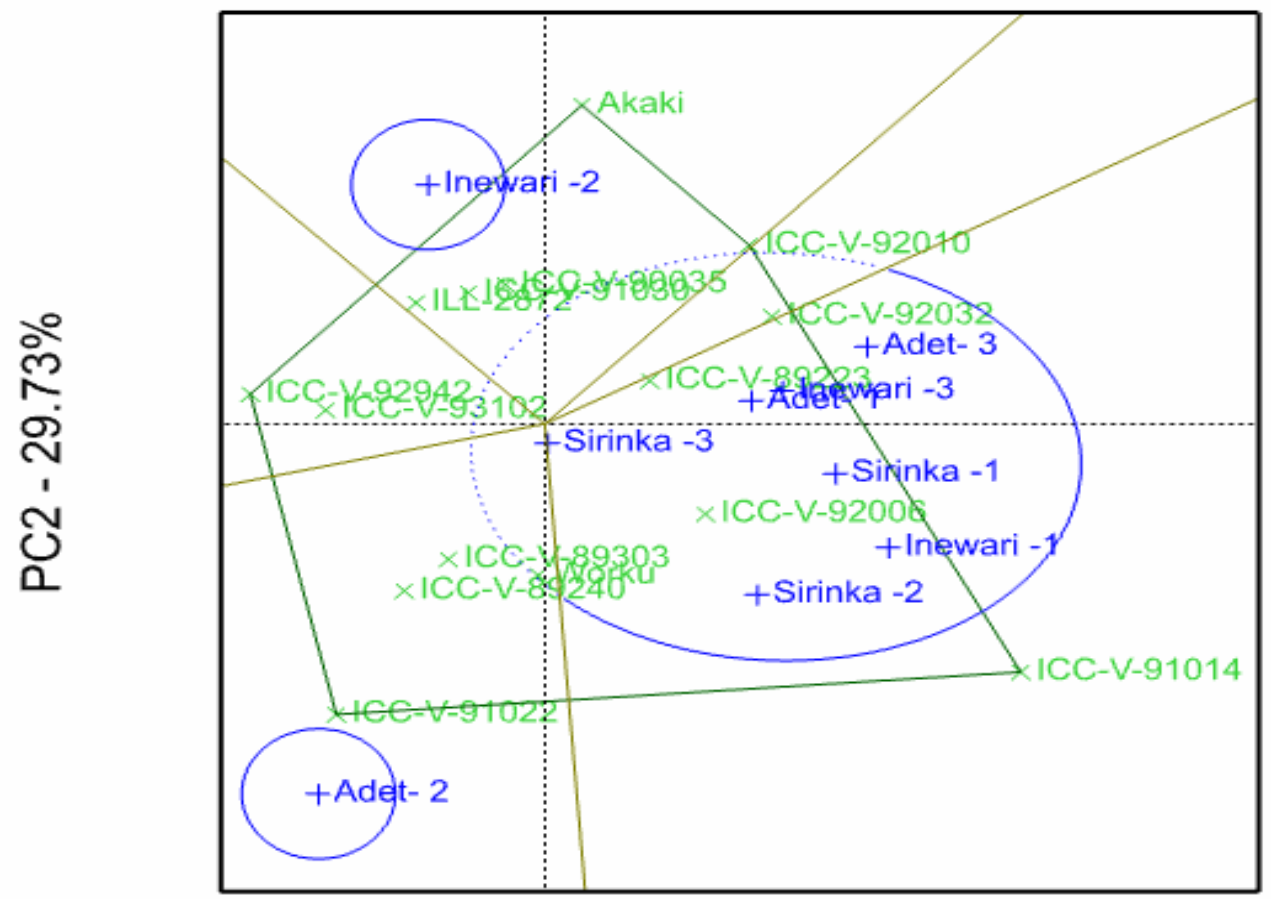

\section{PC1 - 44.24\%}

\begin{tabular}{|cl|}
$\times \times$ & Genotype scores \\
+ & Environment scores \\
\hline & Convex hull \\
\hline & Sectors of convex hull \\
\hline & Mega-Environments \\
\hline
\end{tabular}

Figure 2. GGE biplot of environments showing classifications of environments (agro-ecologies): a showcase for suitability study in chickpea genotypes 


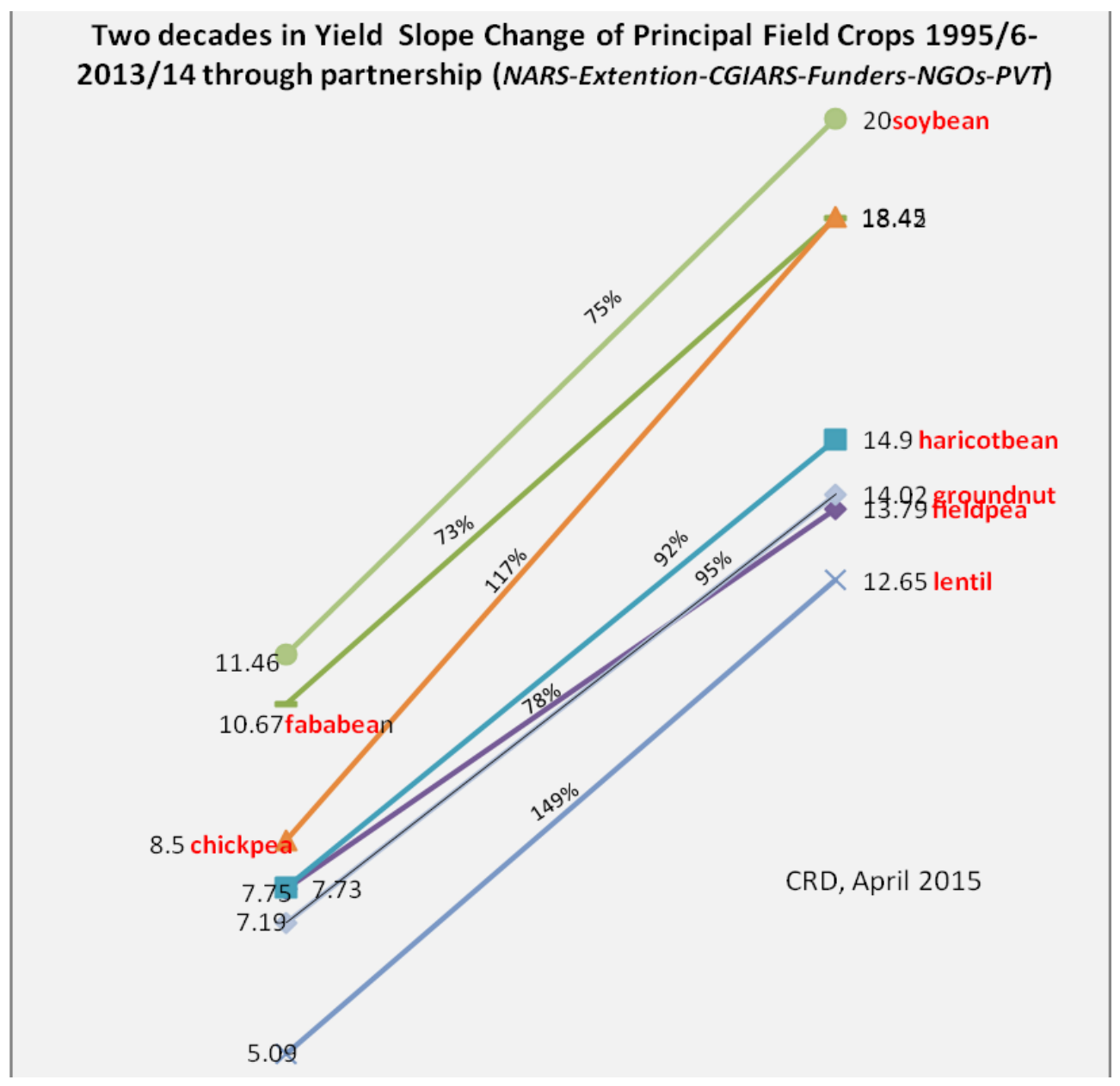

Figure 3. Change in slope of productivity of grain legumes as affected by technology options (developed by the author).Source: 1996-2014)

The same trend holds for the other legumes improvement programs in 30 out of the total of 39 agro- ecological classifications of the country based on the altitudinal, thermal, precipitation and soil factors. Traditionally, because agro-ecological diversity is so significant and massive, all the germplasm development and performance tests are undertaken to cluster the resources on the basis of wider adaptation, elasticity in genetic makeup, or narrow base adaptive groups. These processes would lead the release or recommendation of varieties. Consequently, there are morphological, phenological, physiological and genetic traits explaining the adaptive mechanisms in the different species of the grain legumes.

\section{Yield Gain and Intensification Traits}

The yield gains in grain legumes remain to be the top most important measurement of performance of the research programs. Thousands of germplasm lines obtained from CGIARs as well as national crossing or collections are tested every year for yield in diverse agro-ecologies. The breeding efficiency in terms of the number of varieties released per number of germplasm lines evaluated is roughly $1-2 \%$ in grain legumes. Looking into yield gains, the change in productivity for the different legumes has been different, and can be deemed measure of gain efficiency over time. This must have come from enhanced adoption of technologies with best crop culture combination as a package of Environment x Management x Genetics, which can explain the almost all factors that contribute to potential yield.

The overriding objectives of research in grain legumes have been yield, quality and adaptability traits. In the last two decades, the yield gain for the principal crops ranges between $30-50 \mathrm{~kg} / \mathrm{ha} / \mathrm{season}$ across all the legumes (Figure $3)$. In its existence over the last half a century, there are 180 varieties developed in some 12 principal legumes. All the varieties have been developed for adaptive, productivity and associated favorable and economic traits as compared to the contemporary standard checks. Hence, yield gains over time have been the result of the continuous genetic gains along with management factors (Figure 3 ). The yield gains in over the two decades of 1996 to 2014 among principal grain legumes of Ethiopia including common bean, faba bean, lentil, soybean, chickpea and field pea have been $36,41,41$, 44,45 and $53 \mathrm{~kg} \mathrm{ha}^{-1}$ year $^{-1}$, respectively (Figure 3) [4].The best yield gains was for chickpea that with about $50 \mathrm{~kg} / \mathrm{ha} /$ year, while the best percentage increment goes to lentil which scored $149 \%$ in just two decades [5]. Hence, Figure 3 clearly demonstrates how efficient productivity has 
been realized through intensification. The slope is key unit of gain efficiency as attributes of the improvement program.

However, the genetic improvement still shows that the yield plateau is yet a far setting based on the potentials, indicating the opportunity of further increasing grain yield through breeding. The absolute genetic progress in grain yield was significantly high with a relative genetic progress of $2.13 \%$ and $8.62 \%$ for kabuli and desi type chickpea, respectively [14]. Genetic manipulation through combining favorable genes that confer enhanced performance responses coupled with best crop management practices has warranted intensification with a magnitude ranging 3 to 5 tons/ha in favorable adaptation agro-ecologies, while the national average is about $1.5 \mathrm{t} / \mathrm{ha}$.

\section{Food and Nutritional Security Traits}

Legumes are known for their nutritional values. The nutritional profile of the major food legumes has been analyzed, and existing varieties have been ranked according to their nutritional qualities. Breeding efforts on micronutrient (iron, zinc) enrichment in lentils and common beans have resulted in the release of some micronutrient dense cultivars [13]. A new approach on quality based breeding is taken into account in all the legume programs, though outputs along the line are yet scanty. However, there is a need to develop a scheme for integrating nutritional and general quality parameters in the breeding program so that early generation varietal selection decision making processes can be facilitated.

\section{Cropping System and Compatibility Traits}

Cropping system includes a deliberate integration of different species of crops with different nutrient needs, space, and pest tolerance, with the aim to sustain enhanced production. In the agricultural system of the country, legumes role as part of the cropping is very well recognized. There are research reports that legumes rotation in the cereals alone saves $30 \%$ of $\mathrm{N}$ fertilizer need of the next cropping, which can be applicable to 1.5 million hectares of legume system that have significant value. And, this established knowledge among the wide farming community is traditionally is known as ikir. When such a cropping system is practiced in combination with good agricultural practices combines, it brings about more beneficial system intensification than each of the component crops alone. There is a research report showing sustained and top yield with less bio-threat pressure when best tef varieties of three seasons is rotated with one season of growing of chickpea varieties in central highlands of Ethiopia.

Intercropping of maize and pigeon pea gave land equivalent ratio (LER) of 1.73 indicating $73 \%$ higher land productivity of intercropping over sole cropping [6]. However, there is limited application of intercropping of legumes with cereal crops maintaining the pattern of regulated sequence. Despite this, the agricultural system is still taking negative consequences of the mono-cropping in wheat, sesame, and maize and tef production in many parts of the country.

\section{Market Product Traits}

Grain legumes are leading market commodities in field crops. There are different market class products from the outputs. Both local and export market are competitively operating. The national grain legume research is focusing on marketable traits. Among others, economic traits of interest in the grain legumes include: seed size in faba bean, lentil and chickpea; seed color in faba bean, chickpea, field pea and haricot bean; canning quality in common bean, nutritional quality parameters in lentil, soybean, haricot bean and grasspea [1]. Introduction of Kabuli type of chickpea varieties over the last two decades alone has brought about $20 \%$ market advantages over the desi type varieties (Figure 4) [14]. The same way release of extra bold chickpea, or white beans are found to fetch premium prices as market products.

Over the last four decades alone, the research program has developed some 160 varieties each with defined marketable/consumable traits, and the course the productivity improved twice and seed size has been increased by minimum of three folds [13]. These improvements in gains that are valued between 2000 to 4000 USD per hectare have stimulated the adoption of best production practices thereby leading to enhanced legume productivity of $60 \%$ in a decade. 

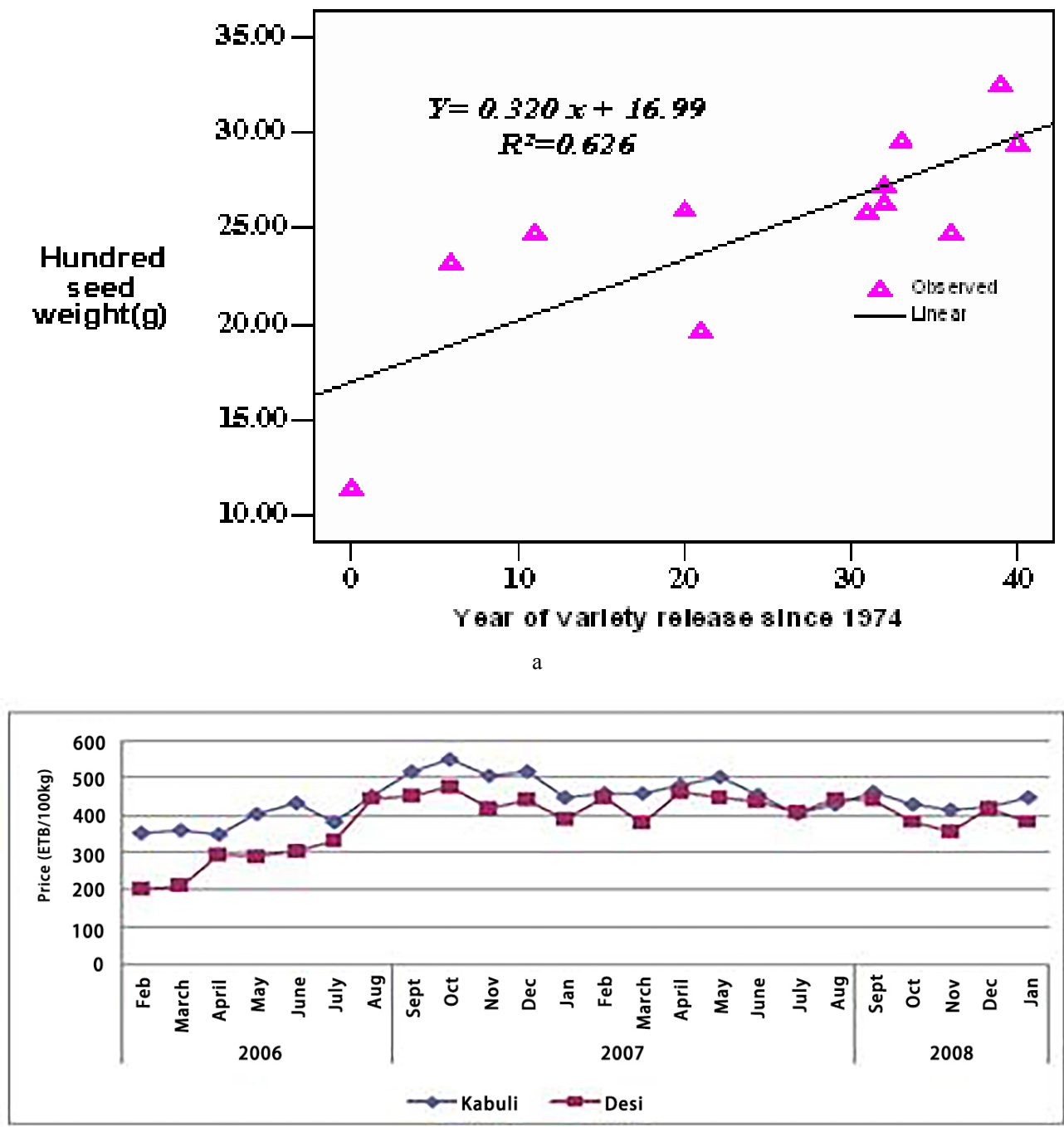

b

Figure 4. The market price differences between desi and kabuli type chickpea products

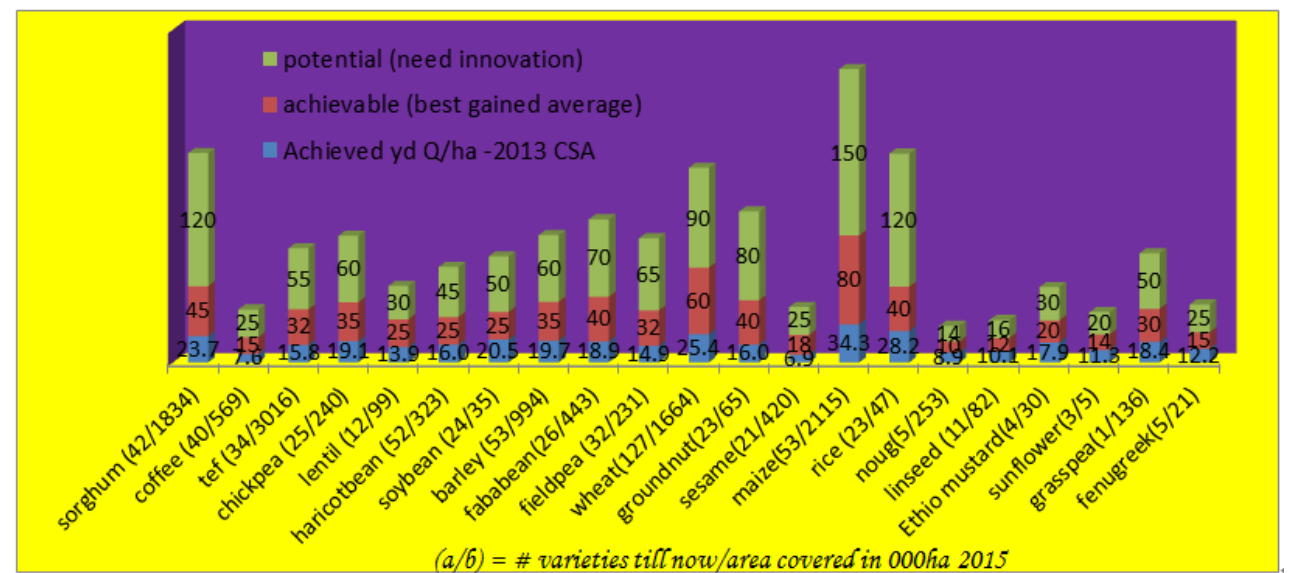

Figure 5. Summary of the performance of Ethiopian field crops production sub=sector and the gaps to be filled up $(\mathrm{Q}=$ quintal $=100 \mathrm{~kg})[\mathrm{reorganized}$ by the author) 


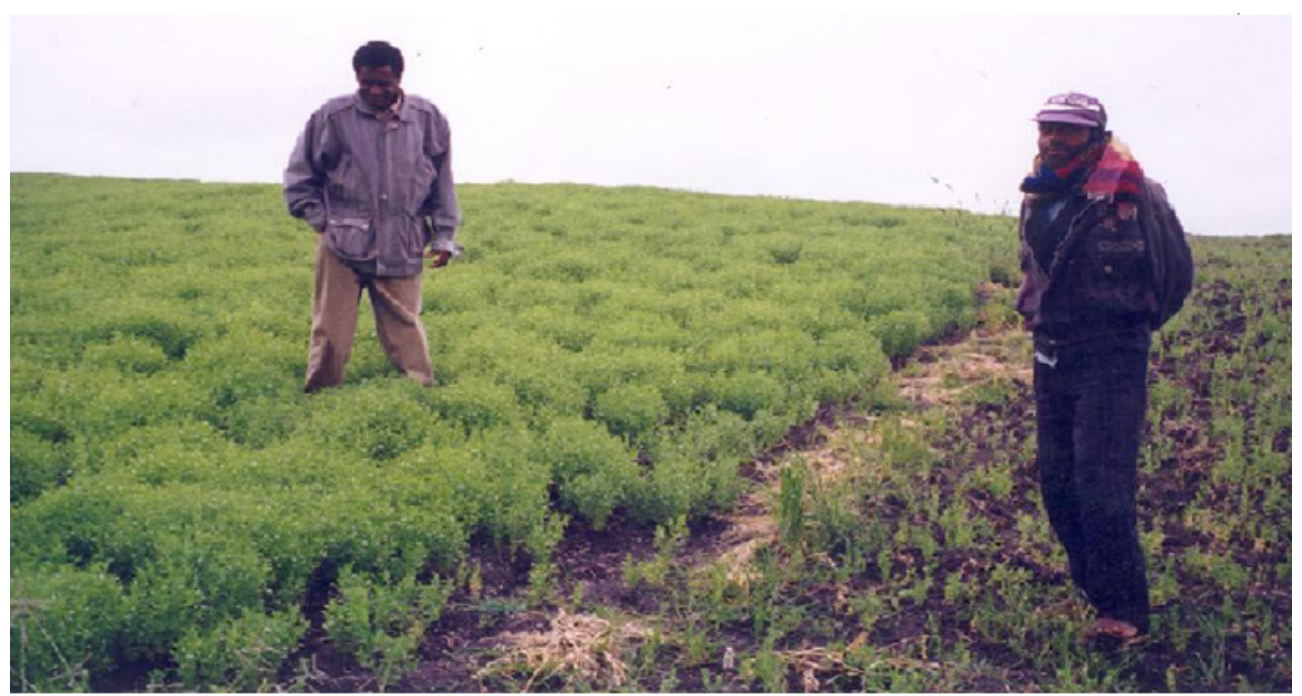

Figure 6. Dr Geletu with improved varity of lentil called Alemaya and a farmer with his cultivar; turning point of convincing (1990s)

\section{Conclusions}

Based on the critical market, nutritional, sustainability roles, grain legumes deserve utmost policy focus in their development and research. The Ethiopian role in the grain legumes industry can even extend to continental significance. With 22.5 million ha and 15.3 million tons, Africa shares $28.5 \%$ global pulse land area and production respectively. However, the continental average productivity is only 0.6 $\mathrm{t} / \mathrm{ha}$, while the global average yield is $0.9 \mathrm{t} / \mathrm{ha}$. Ethiopia, as the leading producer (1968.6 thousand tons) of pulses in the continent [8] and as source of diversity for some grain legumes, can effectively contribute and demonstrate peculiar role in African grain legumes through diversity based intensification as well as economic trait based breeding.

Hence, from the point of the still untapped potential (Figure 4) and the availability of huge market for grain legumes along with their invaluable roles with respect to sustainability and climate change, the grain legumes industry could have indispensable benefits. It is crucial to look into the currently existing gaps like inadequate seed systems, market unpredictability, and emerging pests, through advanced research approach and capacity development. The private sector also needs to be encouraged to take important role in the sector.

Dedication: this review work is dedicated to the late Dr. Geletu Bejiga, who was champion in legume improvement research of Ethiopia and dreamer to improve the livelihood of farmers.

\section{REFERENCES}

[1] Asnake Fikre, Tadesse Sefera, Million Eshete, Kidane Tumsa. 2014. Unraveling breeding traits in Ethiopian legume research hastened intensification and economic gains.. Poster Presentation on the Joint Conference 6th International Food Legumes Research Conference (IFLRC VI) and 7th International Conference on Legume Genetics and Genomics (ICLGG VII). Saskatoon, Canada.

[2] Tamene Temesgen, Mussa Jarso, Wondafrash Mulugeta, Tadesse Sefera and Yeneneh Bekele. 2012. Integrated Seed System in Faba bean Seed Multiplication, Delivery and Impact. In: Adfris T/Wold, Asnake Fikre, Dawit Alemu, Lemma Desalegn and Abebe Kirub (Eds.). The Defining Moments in Ethiopian Seed System. Addis Ababa, Ethiopia

[3] Gemechu Keneni and Musa Jarso. 2009. Comparison of two approaches for estimation of genetic variation for two economic traits in faba bean genotypes grown under waterlogged Verisols. East African Journal of Sciences 3 (1): 95-101.

[4] CSA. 1996-2016. Central Statistics Agency, Federal democratic Republic of Ethiopia. Statistical Bulletins of the years 1996-2016. Field Crops Production and Productivity. Addis Ababa, Ethiopia.

[5] Daniel Admasu Bogale, Firew Mekbib, Asnake Fikre. 2015. Genetic improvement of lentil [Lens culinaris Medikus] between 1980 and 2010 in Ethiopia. Malaysian Journal of Medical and Biological Research 2 (3)

[6] Sustainable Intensification of Maize-Legume based Cropping Systems for Food Security in Eastern and Southern Africa (SIMLESA). Project Progress Report 2015. EIAR.

[7] Adefris T/Wold, Asnake Fikre, Dawit Alemu, Lemma Desalegn and Abebe Kirub (eds). 2012. The Defining Moments in Ethiopian Seed System. Addis Ababa, Ethiopia.

[8] FAO. 2016. Food and Agriculture Organization (FAO) of the United Nations, FAOSTAT.fao.org

[9] Alemayehu Mengistu. 2003. Country Pasture/Forage Resource Profiles .http://www.fao.org/ag/agp/agpc/doc/counp rof/ethiopia/Ethiopia.htm\#1. Addis Ababa University, Ethiopia.

[10] Thudi M, Upadhyaya HD, Rathore A, Gaur PM, Krishnamurthy L, et al. 2014. Genetic dissection of drought and heat tolerance in chickpea through genome-wide and 
candidate gene-based association mapping approaches. PLoS ONE 9(5): e96758. doi:10.1371/journal.pone.0096758

[11] Getachew Tilahun, Firew Mekbib, Asnake Fikre and Million Eshete. 2015. Genotype $\mathrm{x}$ environment interaction and stability analysis for yield and yield related traits of Kabuli-type Chickpea (Cicer arietinum L.) in Ethiopia. African Journal of Biotechnology 14(18); 1564-1575.

[12] Wondafrash Mulugeta, and Dejene Girma. 2015. Genotype x environment interaction and stability analysis of chickpea (Cicer arietinum L.) in Northern part of Ethiopia. Ethiop. J. Appl. Sci. Technol. 5(2): 21-32.
[13] MoA, 2014. Ministry of Agriculture, Animal and Plant Health Regulatory Directorate, Crop Variety Register, Issue No. 15, Addis Ababa, Ethiopia.

[14] Dagnachew Bekele., Asnake Fikre., Million Eshete, Lijalem Korbu, and Nigusie Girma (in press) Genetic progresses achieved in Ethiopian chickpea (Cicer arietinum L.) breeding program based on grain yield and seed size. Proceedings on Harnessing Chickpea Value Chain for Nutrition Security and Commercialization of Smallholder Agriculture in Africa. Bishoftu, Ethiopia. 